\title{
KEARIFAN LINGKUNGAN DALAM PENGELOLAAN HUTAN, TANAH DAN SUNGAI DI DESA SINGENGU, KECAMATAN KOTANOPAN KABUPATEN MANDAILING NATAL, SUMATERA UTARA (Environmental Wisdom on Management of Forest, Soil and River in Singengu Village, Kotanopan District, Mandailing Natal Regency North Sumatera)
}

\author{
Cut Nuraini* \\ Jurusan Teknik Arsitektur, Institut Teknologi Medan (ITM) \\ Jln. Gedung Arca No 52, Medan 20217. \\ *No Telp. (061)7363771, Ext.108. Fax. (061)7347954. Email : nurainiicut@yahoo.com.
}

Diterima: 1 Juni 2014

Disetujui: 9 Desember 2014

\begin{abstract}
Abstrak
Desa Singengu adalah desa pertama yang dibangun oleh leluhur orang-orang marga Lubis pada saat turun gunung. Warga desa Singengu meyakini bahwa hutan, tanah dan sungai tidak hanya digunakan sebagai tempat untuk beraktivitas mencari nafkah, tetapi juga memiliki nilai ias (suci). Area-area tertentu di dalam hutan dan sungai dianggap taboo (pantang) untuk dimasuki. Pelanggaran atas larangan tersebut diyakini akan mendapatkan kutukan dari roguk (penunggu). Penelitian ini terkait dengan dua realitas, yaitu tangible (nyata) dan intangible (tidak nyata) sehingga paradigma yang tepat untuk menggali makna dibalik fenomena dua realitas tersebut adalah fenomenologi. Metode fenomenologi yang digunakan adalah fenomenologi Husserlian. Hasil penelitian menunjukkan bahwa pengelolaan, pemanfaatan dan pelestarian hutan dan sungai dilakukan melalui dua cara, yaitu peraturan tertulis dalam bentuk uhum dohot ugari (aturan/ketentuan adat yang dibuat oleh leluhur) serta mitos tentang rarangan (larangan) dan roguk (penunggu) sehingga beberapa area tertentu menjadi 'terlarang' bagi aktivitas manusia. Warga desa Singengu mengelola, memanfaatkan dan melestarikan lingkungan hutan-sungai melalui konsep taboo (pantang) sebagai pangolat (pembatas) tempat, sehingga terbentuklah dua jenis tempat, yaitu tempat-tempat yang boleh dilakukan aktivitas di dalamnya dan tempat-tempat yang dilarang.
\end{abstract}

Kata kunci: hutan larangan, kearifan lingkungan, lubuk larangan, mata air, pelestarian hutan.

\begin{abstract}
Singengu is the first village that was built by the ancestors of the Lubis clan people on the way down the mountain. Singengu people believe that forest, soil and river are not only used as a place to indulge for a living, but it also has ias (sacred) value. Specific areas within the forest and river is considered taboo (abstinence) to be entered. Violation of the ban is believed to be getting the curse of roguk (gatekeepers/guardian). Research on systems management, utilization and conservation of forest, soil and river is related with two realities, namely the tangible (real) and intangible (notreal) so that the appropriate paradigm to explore the meaning behind two reality phenomena is phenomenology method. Phenomeology method which is used is Husserlian phenomenology. The results showed that the system of management, utilization and conservation of forest and river done in two ways, namely in the form of written rules uhum dohot ugari (rules /regulations made by ancestral custom) and myths about rarangan (ban) and roguk (gatekeepers) so that certain areas be 'forbidden'/prohibited for human activities. Singengu people manage, utilize and conserve the forest, soil and river environments through concepts taboo (abstinence) as pangolat (barrier/delimiter) places, thus forming two types of places, places that may do the activities in it and forbidden places.
\end{abstract}

Keywords: forbidden-forest, environmental wisdom, forbidden-river, spring water and forest conservation.

\section{PENDAHULUAN}

Hutan, tanah dan sungai di kawasan Mandailing Julu adalah bagian dari kekayaan alam Sumatera yang sebagian besar areanya berfungsi sebagai Taman Nasional Batang Gadis. Kawasan tersebut terdiri atas rangkaian tor (gunung)/dolok (bukit) yang mempunyai potensi kekayaan keanekaragaman jenis flora dan fauna (Harahap, 2004). Saat ini, kelestarian Taman Nasional tersebut mulai terganggu dengan keberadaan aktivitas pertambangan emas di beberapa tempat, terutama kawasan hutan-hutan yang ada di tor (gunung). Isu ini menjadi menarik, karena warga Mandailing Julu tidak setuju dengan penambangan yang dilakukan oleh pihak asing. Penambangan yang dilakukan dianggap telah melanggar aturan adat yang sejak lama ditaati dan dihormati oleh leluhur. Isu tentang penambangan yang dilakukan oleh pihak asing di tanah Mandailing yang dianggap melanggar adat leluhur sangat kontras dengan fenomena yang ditemukan pada salah satu desa yang hingga saat ini tetap mempertahankan tradisi pengelolaan hutan, tanah dan sungainya 


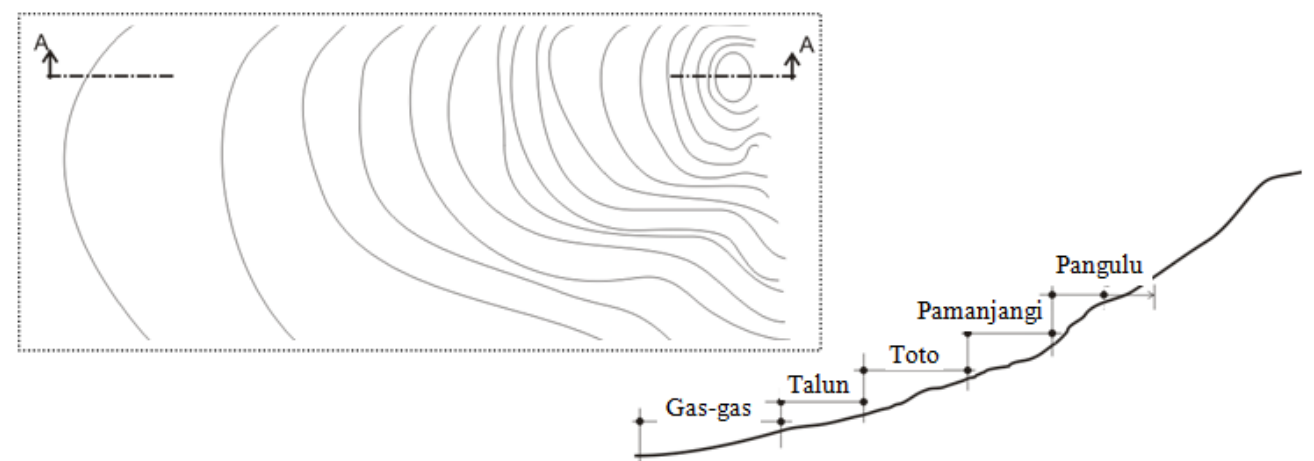

Gambar 1. Struktur tor (gunung) dalam catatan uhum dohot ugari (Nuraini, 2014).

sesuai dengan aturan-aturan yang telah ditetapkan leluhur, yaitu desa Singengu (Nuraini, 2011). Desa Singengu adalah desa tertua sebagai induk dari semua desa-desa yang ada di Mandailing Julu.

Di masa sekarang, aturan-aturan adat tertulis maupun tidak tertulis yang diketahui oleh warga desa Singengu tidak hanya diterapkan pada lingkungan sekitar rumah tinggal (Nuraini, 2013), tetapi juga selalu diterapkan dalam memelihara, menjaga dan memanfaatkan potensi hutan, tanah dan sungai di lingkungan mereka sehingga selalu terjaga dari kerusakan dan kehancuran. Hutan, tanah dan sungai di desa Singengu telah menjadi bagian dari kehidupan masyarakatnya sekaligus sebagai sumber kehidupan.

Peraturan Menteri Dalam Negeri tentang penataan Ruang Terbuka Hijau Perkotaan (Anonim, 2007) mendeskripsikan pengertian dari kearifan lingkungan, yaitu kecerdasarn, kreativitas, inovasi dan dapat juga pengetahuan tradisional masyarakat lokal berupa kearifan ekologis dalam pengelolaan dan pelestarian ekosistem/sumber daya alam lingkungan sekitar. Kearifan lingkungan juga dapat berupa kearifan sosial dalam bentuk tatanan sosial yang menciptakan keharmonisan dan kedinamisan hidup bermasyarakat yang telah dijalani secara turun temurun dan menunjukkan adanya manfaat yang diterima oleh masyarakat setempat dalam membangun peradabannya. Kearifan lingkungan perlu terus dijaga dan dipertahankan/dilestarikan agar dapat tercipta keseimbangan hidup dan masyarakat desa memiliki cara sendiri dalam melestarikan lingkungannya.

Nenek moyang orang-orang Singengu yang dulu hidup di tor (gunung) telah memiliki pengetahuan tentang pengelolaan, pemanfaatan dan pelestarian hutan, tanah dan sungai. Hal ini dibuktikan dengan ditemukannya sejumlah dokumen tua oleh seorang penulis asal Mandailing, yaitu Basyral Hamidi Harahap yang berisi tentang beberapa aturan uhum dohot ugari (hukum adat dan peradatannya). Hukum adat tersebut mulai dibukukan pada tahun 1894 yang terdiri dari 85 pasal, mencakup segala aspek kehidupan masyarakat, termasuk pemanfaatan hutan, tanah dan sungai (Adatrechtbundel-1936-Deel XXXVIII: Gajo-Alas-en Bataklanden-serie G: Gajo-Alas- en Bataklanden; No.79: Adatrechtsregelen van Groot Mandailing en Batang Natal (1894:285-325) dalam Harahap, 2004). Di dalam hukum adat tersebut pemanfaatan tanah hutan memiliki kategori tersendiri (Gambar 1), yaitu Gasgas, yaitu bekas ladang yang di atasnya masih tumbuh pohon-pohon besar seperti enau, petai, durian, bambu dan lainlain; Talun atau hutan muda bekas ladang dan akan ditanami secara bergilir antara 4 sampai 7 tahun tiap bidang tanah yang tersedia ssebagai talun; Toto, yaitu sebidang tanah yang dirambah sendiri di hutan untuk dimanfaatkan sendiri seluas masingmasing sisinya 10 depa; Pamanjangi, tanah yang dirintis di hutan selebar 5 depa dan panjangnya terserah sepanjang yang dikehendaki untuk dimanfaatkan bagi kesejahteraan sendiri dan Pangulu, tanah yang telah diusahakan di hutan dan dapat diperluas sampai 50 depa ke arah pedalaman hutan.

Pengelolaan lingkungan yang dilakukan oleh suatu kelompok masyarakat tertentu juga ditemukan pada perencanaan dan pengelolaan hutan Wonosari di kecamatan Ngawen kabupaten Gunung Kidul (Nurhadi dkk., 2012). Menurut Nurhadi dkk (2012) kearifan lingkungan dalam mengelola hutan adat Wonosari bersumber pada dua hal, yaitu adanya mitologi dan sejarah hutan. Hutan telah memberikan manfaat yang besar bagi penduduk sekitarnya. Masyarakat yang tinggal di sekitar kawasan hutan mempunyai kesadaran mitologi dan realitas untuk mengelola hutan dan tetap ingin merasakan manfaat yang positif dari keberadaan hutan tersebut. Bagi suatu kelompok masyarakat, hutan merupakan salah satu kekayaan sosial budaya karena pemanfaatan dan proses sosial budaya yang terjadi di dalamnya seperti yang ditemukan di kawasan pegunungan Arfak, Papua (Salosa dkk, 2014).

Fenomena tersebut menunjukkan bahwa ada strategi masyarakat lokal dalam mempertahankan potensi budaya sebagai kearifan lingkungan setempat dengan cara mereka sendiri, termasuk desa Singengu. Permasalahannya adalah seperti apa 
kearifan lokal dalam pengelolaan hutan, tanah dan sungai yang dilakukan oleh masyarakat desa Singengu. Penelitian ini bertujuan untuk mengungkapkan kearifan lingkungan dalam mengelola tanah, hutan dan sungai yang dilakukan oleh masyarakat di desa Singengu.

\section{METODE PENELITIAN}

\section{Waktu dan Lokasi}

Penelitian ini merupakan bagian dari penelitian disertasi yang dilakukan selama kurun waktu enam bulan sejak April sampai dengan September 2010. Lokasi penelitian ini adalah Desa Singengu, Kecamatan Kotanopan, Kabupaten Mandailing Natal, Sumatera Utara. Penelitian ini menggunakan paradigma fenomenologi dengan metode eksploratif-kualitatif dan analisis induktif dengan tiga tahapan reduksi.

\section{Prosedur Penelitian}

Penelitian dimulai dengan grandtour dan dilanjutkan dengan minitour ke lapangan untuk mengumpulkan data (fisik dan non-fisik/sosialbudaya) terkait hutan, tanah dan sungai melalui teknik wawancara dan sketsa lapangan. Semua data yang diperoleh dicatat dalam logbook dan dianalisis melalui analisis induktif. Setiap data yang diperoleh di lapangan langsung dianalisis. Proses analisis induktif berlangsung secara terus menerus melalui tiga tahapan reduksi, yaitu reduksi fenomenologi, reduksi eidetik dan reduksi transendental.

\section{HASIL DAN PEMBAHASAN}

\section{Pengelolaan Hutan, Tanah dan Sungai}

Ada dua bentuk aturan tentang pengelolaan, pemanfaatan, pelestarian hutan, tanah dan sungai di desa Singengu, yaitu aturan tertulis, yaitu uhum dohot ugari (aturan dan ketentuan ) dan aturan tidak tertulis, yaitu mitos tentang inganan rarangan (tempat larangan). Aturan tertulis yang ditemukan dalam sebuah dokumen tua menunjukkan bahwa, leluhur orang-orang Mandailing telah memiliki pengetahuan tentang pengelolaan dan pemanfaatan hutan. Jika digambarkan secara konstruktif berdasarkan olah data Harahap (2004), pemanfaatan hutan dan tanah di tor (gunung) dan dolok/bukit dapat dilihat pada Gambar 2. Pada Gambar 2 jelas terlihat, bahwa leluhur orang-orang Mandailing Julu telah memberikan/menyusun aturan tentang penggunaan tanah di tor (gunung) yang dapat dimanfaatkan sebagai ladang dan kebun. Pada batas tertentu, tidak boleh diganggu dan digunakan sebagai kebun yaitu kawasan hutan pedalaman yang didalamnya terdapat naborgoborgo (yang lembab-lembab) dan identik dengan mual (mata air). Pembatas sebagai penanda tempatnya adalah harangan rarangan (hutan larangan).

Harangan rarangan atau hutan larangan adalah kawasan yang dilarang untuk dimasuki. Warga desa Singengu secara turun temurun meyakini bahwa kawasan hutan larangan ada roguk-nya (penunggu) yaitu Jihin (jin) sehingga tidak boleh dimasuki. Mitos lain yang berkembang adalah adanya roguk di naborgo-borgo (tempat yang lembab-lembab). Warga mengenal Naborgoborgo sebagai mual (mata air) di tor (gunung) dan dolok (bukit). Air yang digunakan untuk kebutuhan sehari-hari adalah air yang dialirkan melalui pipapipa dari dua bukit yang mengapit desa Singengu. Ladang, kobun (kebun) dan hutan desa Singengu terdapat di kawasan Bukit Parkutahan, sedangkan bukit Tawar di Utara adalah bagian dari kawsan desa Hutapadang.

Tempat larangan adalah tempat-tempat yang dilarang untuk dimasuki, dimiliki, dimanfaatkan dan digunakan sebagai wadah atau ruang untuk beraktivitas. Tempat-tempat yang 'terlarang' untuk dimasuki oleh semua warga adalah bagian tertentu dari sungai yang telah dijadikan lubuk larangan dan harangan rarangan (hutan larangan). Tetapi, pada momen-momen tertentu, lubuk larangan dan harangan rarangan (hutan larangan) dapat dimasuki oleh kaum laki-laki. Lubuk larangan menjadi tidak terlarang bagi kaum laki-laki pada saat Idul Fitri atau lebaran, yaitu pada saat panen ikan dilakukan. Bahkan, di momen panen ikan tersebut, semua laki-laki dari desa tetangga diundang untuk hadir dan ikut memeriahkan acara panen ikan tersebut. Demikian juga dengan harangan rarangan (hutan larangan), pada saat-saat tertentu kaum laki-laki dapat memasuki area tersebut jika tujuannya adalah untuk kemaslahatan warga desa Singengu. Contohnya, memperbaiki saluran air dari naborgo-borgo yang terletak di dalam hutan larangan (harangan rarangan) atau membersihkan dan menjaga sumber air naborgoborgo agar tidak tercemar dan rusak. Pada Gambar 3 disajikan struktur bukit Parkutahan dan pola pemanfaatannya

Daerah sungai yang paling hulu dan mengarah atau dekat dengan muara partontang (muara tempat bertemunya tiga sungai yang bertentangan arah datangnya) juga merupakan area terlarang. Di masa lalu tempat tersebut digunakan oleh leluhur sebagai tempat untuk bersemedi, melakukan ritual penyembahan Sipelebegu (arwah) dan Datu (Sang Pencipta). Tempat di sekitar muara partontang tersebut sangat dilarang untuk didekati, kecuali oleh seorang raja. Warga meyakini bahwa di tempat tersebut juga ada roguk-nya (penunggu). Apabila ada warga memasuki atau menjamah kawasan- 


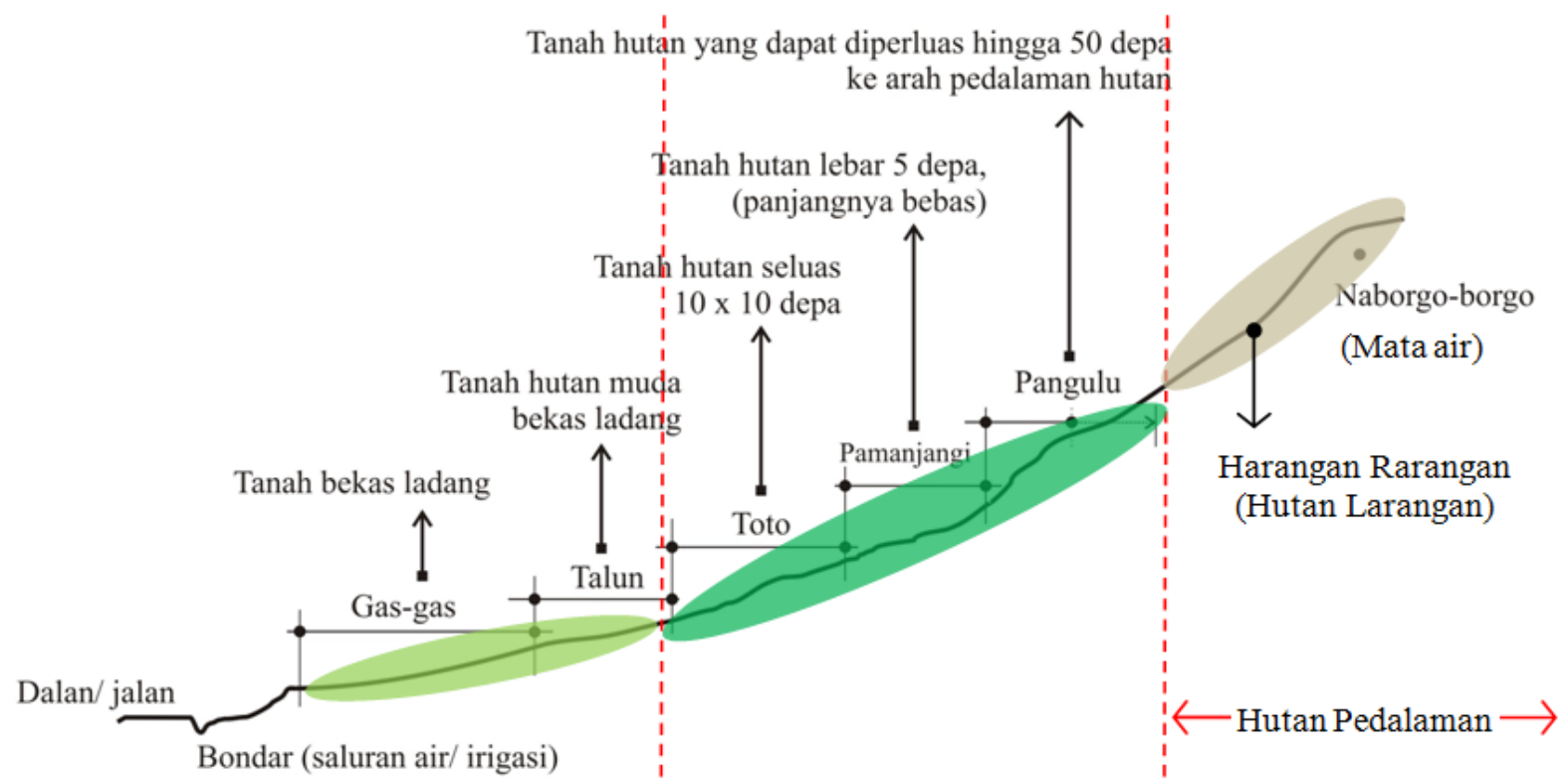

Gambar 2. Struktur tor (gunung) dan pola pemanfaatannya.

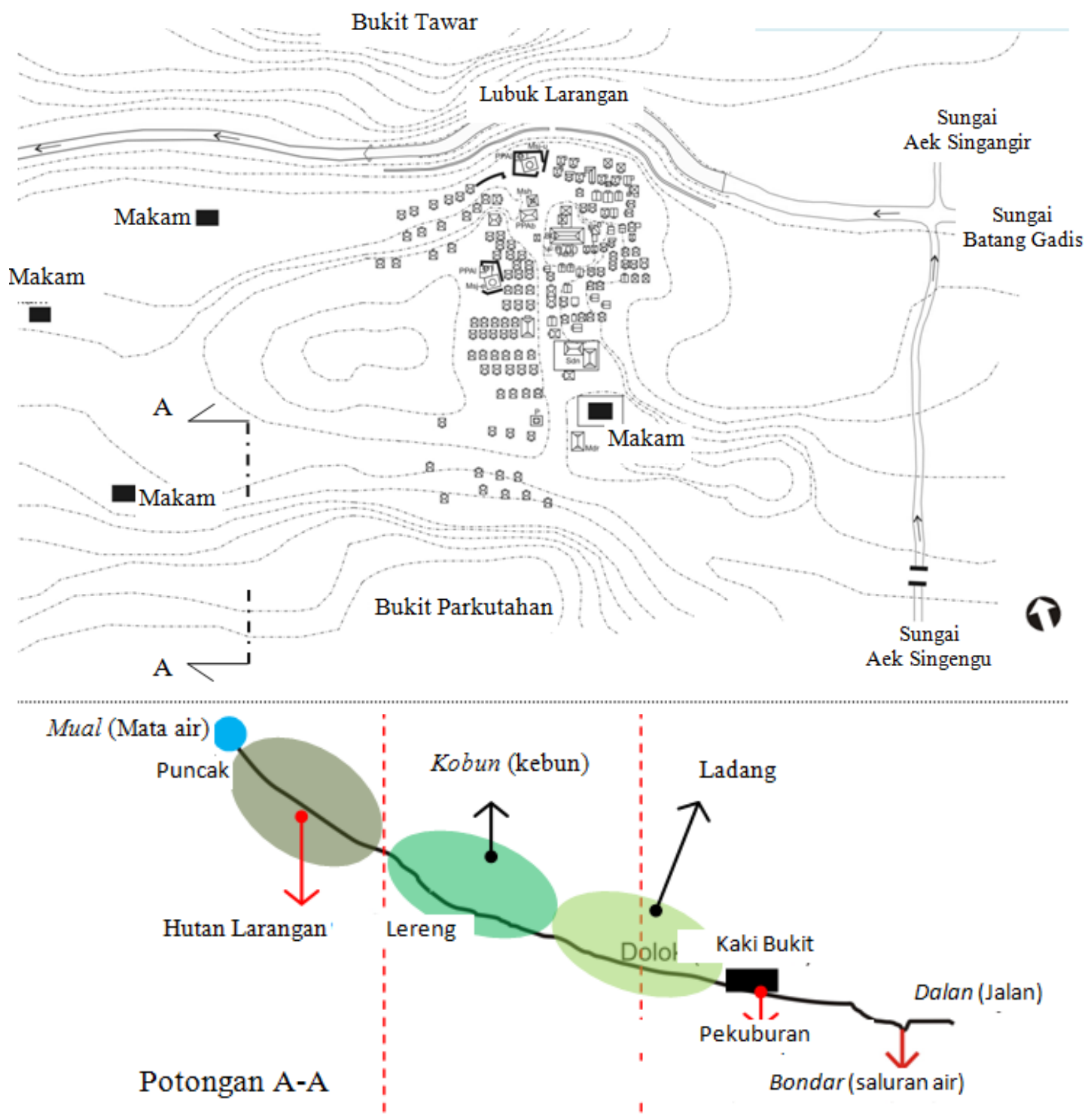

Gambar 3. Struktur bukit Parkutahan dan pola pemanfaatannya. 

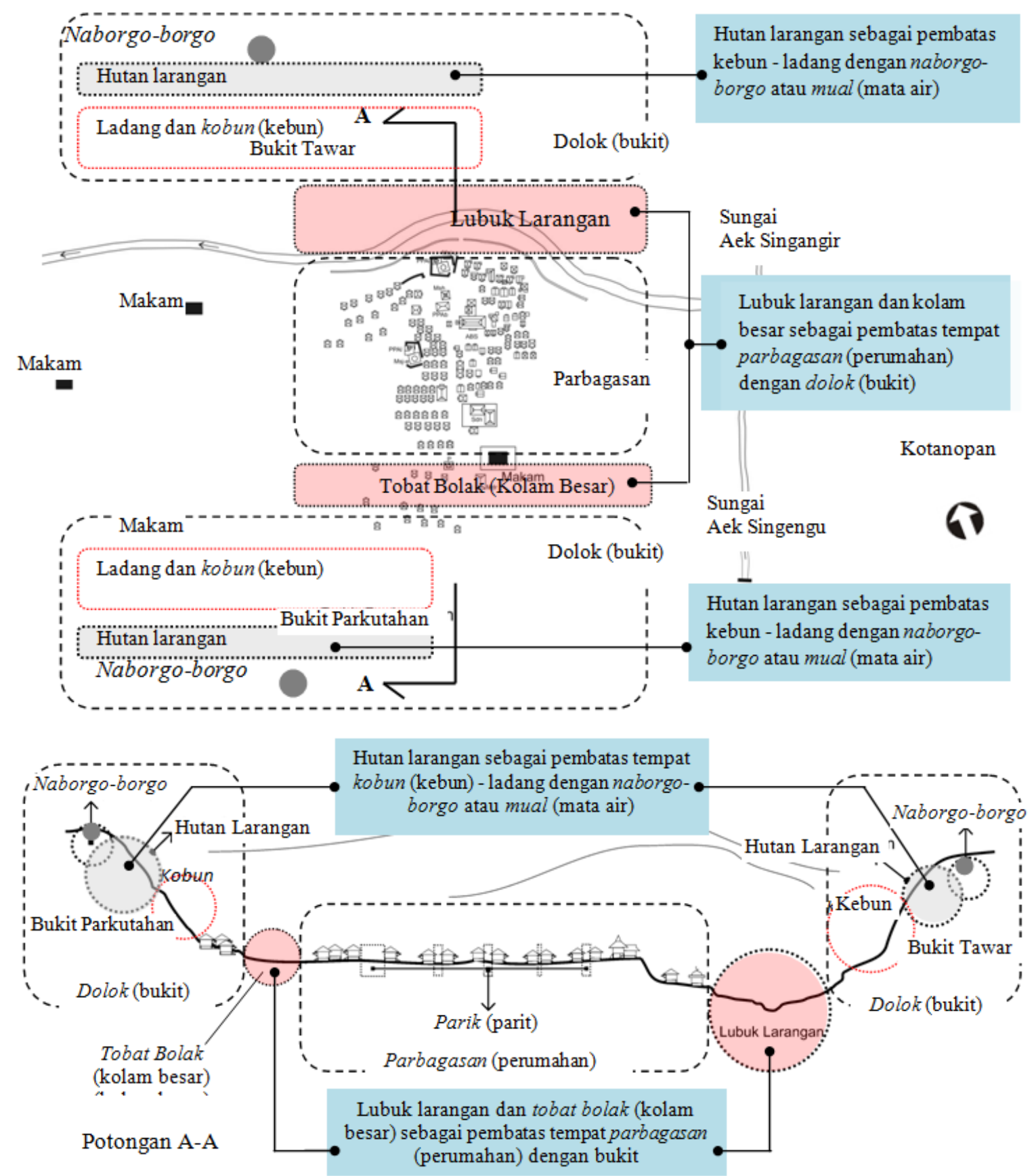

Gambar 4. Taboo (pantang) dan Pangolat (pembatas tempat) sebagai bentuk pengelolaan hutan, tanah dan sungai.

kawasan yang dilarang tersebut, maka mereka diyakini akan mendapatkan kutukan dari roguk.

Kearifan lingkungan desa Singengu dalam hal pengelolaan, pemanfaatan dan pelestarian hutan, tanah dan sungai diwujudkan dalam bentuk istilah lokal, yaitu taboo (pantang) dan pangolat (pembatas tempat). Taboo di kehidupan warga desa Singengu, dua di antaranya yaitu taboo memasuki hutan larangan dan lubuk larangan di bagian sungai. Pangolat menegaskan fungsi-fungsi lahan permukiman di desa Singengu sebagai parbagasan (perumahan) dan area luar. Pada Gambar 4 disajikan ilustrasi taboo (pantang) dan pangolat (pembatas tempat) sebagai bentuk pengelolaan hutan, tanah dan sungai

\section{Taboo dan Pangolat sebagai kearifan lingkungan desa Singengu}

Taboo (pantang) sebagai bentuk larangan terhadap segala perbuatan yang akan mencemari kawasan hutan larangan yang didalamnya terdapat mual (mata air) bermakna sakral dan suci. 
Naborgo-borgo yang identik dengan mual (mata air) di puncak gunung dan bukit, dulu digunakan oleh leluhur sebagai media untuk memuja Sipelebegu (arwah) dan Datu (Sang Pencipta). Di masa sekarang, air yang berasal dari mual (mata air) di gunung dan bukit digunakan sebagai media untuk bersuci ketika akan sholat. Air dari puncak bukit tersebut dialirkan ke mesjid-mesjid, musholla, rumah-rumah penduduk dan ke pancuran-pancuran mandi. Saat ini, air bersih dari perusahaan air minum telah masuk ke desa Singengu, tetapi warga lebih memilih untuk menggunakan air yang langsung dialirkan dari mata air di bukit.

Pangolat (pembatas) bermakna pola tata guna tanah atau lahan. Warga desa Singengu secara sadar memiliki pemahaman tentang pola-pola tata guna lahan atas tanah-tanah permukiman mereka sedemian rupa, sehingga setiap tempat digunakan sesuai dengan fungsinya. Tor (gunung) bagi warga Singengu dianggap sebagai tempat asal leluhur, bahkan leluhur di makamkan di tor. Di tempat yang sekarang, yaitu di tapian (dataran di tepi sungai) bukit merupakan simbol tor dan warga Singengu menempatkan makam-makam di bukit sebagai simbol tempat asal dan tempat kembali. Oleh karena itu, kawasan parbagasan (perumahan) sebagai tempat tinggal harus dibatasi dengan tempat makam, yaitu bukit dengan pangolat (pembatas tempat). Dua wujud pangolat yang membatasi kawasan parbagasan dengan kawasan bukit adalah sungai dan lubuk larangan di arah Utara dan tobat bolak (kolam besar) di arah Selatan.

Taboo memasuki lubuk larangan di sungai bermakna konservasi area sungai sebagai salah satu tempat mencari nafkah bagi warga desa Singengu. Kawasan sungai Batang Gadis sejak lama dikenal dengan kandungan emasnya. Emas-emas yang ada di sungai tersebut biasanya juga memiliki musim. Jika sawah belum bisa dipanen, hasil kebun dan ladang juga belum bisa dijual, saat itulah emasemas di sungai mulai dapat di-‘dulang'. Dengan adanya larangan tersebut, area sungai menjadi terjaga dari eksplorasi berlebihan.

\section{KESIMPULAN}

Sistem pengelolaan hutan, tanah dan sungai di desa Singengu dilakukan melalui dua cara, yaitu peraturan tertulis dalam bentuk adat uhum dohot ugari (aturan/ketentuan adat yang dibuat oleh leluhur) dan adanya mitos tentang rarangan (larangan) atau taboo (pantang) dan mitos roguk (penunggu) sehingga beberapa area tertentu menjadi 'terlarang' bagi aktivitas manusia. Warga desa Singengu secara sadar mengelola, memanfaatkan dan melestarikan lingkungan hutan, tanah dan sungai melalui konsep taboo (pantang) sebagai pangolat (pembatas) tempat, sehingga terbentuklah dua jenis tempat, yaitu tempat-tempat yang boleh dilakukan aktivitas di dalamnya dan tempat-tempat yang dilarang.

Sistem pengelolaan hutan, tanah dan sungai yang dilakukan atas dasar nilai-nilai lokal yang diyakini secara terus menerus telah menjadi modal warga desa Singengu dalam mengatur ruang-ruang tempat hidupnya, sehingga mereka dapat terus hidup damai berdampingan dengan alam sekitarnya.

\section{DAFTAR PUSTAKA}

Anonim, 2007. Peraturan Menteri Dalam Negeri Nomor 1 Tahun 2007 tentang Penataan Ruang Terbuka Hijau Perkotaan, Depdagri-RI, Jakarta.

Harahap, B.H., 2004. Madina (Mandailing Natal) yang Madani, Pemerintahan Kabupaten Mandailing Natal, Sumatera Utara, Medan.

Nuraini, C., 2011. Arsitektur Permukiman desa Singengu, Tugas Mata Kuliah Arsitektur Vernakular, Program Doktor Teknik Arsitektur, Universitas Gadjah Mada, Yogyakarta.

Nuraini, C., 2013. Pakarangan di Permukiman Desa Singengu, Mandailing Julu, Sumatera Utara, Jurnal Forum Teknik, 35(2):2-4.

Nuraini, C., 2014. Bincar-Bonom sebagai Basis Tata Ruang Permukiman Desa Singengu, Disertasi, Program Doktor Teknik Arsitektur, Universitas Gadjah Mada, Yogyakarta.

Nurhadi, A., Setiawan, B., dan Baiquni, 2012. Kearifan Lingkungan dalam Perencanaan dan Pengelolaan Hutan Wonosadi Kecamatan Ngawen, kabupaten Gunung Kidul. Jurnal Manusia dan Lingkungan,19(3):232-234.

Salosa, S.T., Awang, S.A., Suryanto, P., dan Purwanto, R.H., 2014. Hutan dalam Kehidupan Masyarakat Hatam di Lingkungan Cagar Alam Pegunungan Arfak, Jurnal Manusia dan Lingkungan, 21(3):349-555. 